\title{
Strategi Pengembangan Trenggalek Agropark melalui Animal Based Tourism di Kabupaten Trenggalek
}

\section{Trenggalek Agropark Development Strategy by Animal-Based Tourism in Trenggalek Regency}

\author{
A. Martiningsih*, Ismulhadi, dan A. Warnaen \\ Politeknik Pembangunan Pertanian, Malang \\ *E-mail: anjumma90@gmail.com \\ (Diterima: 20 Juli 2019; Disetujui: 29 September 2019)
}

\begin{abstract}
ABSTRAK
Ketertarikan generasi muda untuk berkecimpung dalam sektor pertanian dan peternakan semakin hari semakin menurun. Hal ini dikarenakan sektor pertanian dianggap kurang menghasilkan dan menjadi petani dinilai sebagai kasta rendah. Salah satu upaya yang dilakukan pemerintah dalam bidang pembangunan pertanian dan peternakan adalah dengan mendirikan Trenggalek Agropark. Tujuan dari kajian ini adalah untuk merumuskan strategi terbaik pengembangan Trenggalek Agropark melalui animal based tourism. Model analisis yang digunakan adalah SWOT dan QSPM. Berdasarkan diagram SWOT, maka strategi SO adalah strategi yang sesuai dengan kondisi Trenggalek Agropark. Strategi yang dirumuskan dari faktor internal dan eksternal melalui FGD dengan Dinas Pertanian dan Pangan, PPL dan generasi muda berdasarkan prioritas diantaranya sebagai berikut: a) melengkapi sarana dan prasaran serta melakukan diklat bagi SDM pendamping; b) menyiapkan lahan untuk penanaman HPT guna mendukung penerapan prinsip kesejahteraan hewan (animal welfare); c) menyediakan showroom untuk memasarkan pruduk pertanian dan peternakan yang telah dihasilkan oleh petani/peternak Kabupaten Trenggalek.
\end{abstract}

Kata kunci: animal based tourism, animal welfare, generasi muda, strategi

\section{ABSTRACT}

The interest of the young generation to engage in the agriculture and livestock sector is decreasing every day. the agricultural sector is considered less productive and low caste. One of the efforts made by the government in the field of agricultural and livestock development was by establishing Trenggalek Agropark. The purpose of this study is to formulate the best strategy for developing Trenggalek Agropark through animal-based tourism. The analytical model used is SWOT and QSPM. Based on the SWOT diagram, the SO strategy is a strategy that is accordance with the conditions of Trenggalek Agropark. This strategy formulated based internal and external factors through FGD with the Office of Agriculture and Food Trenggalek Regency, extension worker and the young generation. The priority strategies according QSPM are a) completing facilities, infrastructure and conducting training for companion human resources; b) preparing the land for planting grass to support the application of the principles of animal welfare; $c$ ) provide a showroom to market the locally made of agricultural and livestock products.

Keywords: animal-based tourism, animal welfare, strategy, young generation

\section{PENDAHULUAN}

Sektor pertanian, perdagangan, hotel serta restoran masih memiliki kebutuhan tenaga kerja terbanyak dibandingkan dengan sektor usaha lainnya. Jumlah tenaga kerja pertanian mengalami penurunan hampir di semua kelompok usia. Jumlah generasi muda yang beraktivitas di pertanian yakni tenaga kerja pertanian berusia kurang dari 35 tahun masih sedikit bahkan diproyeksikan akan terus menurun sedangkan petani berusia 
lanjut terus akan meingkat (Nugroho et al., 2018). Hasil penelitian Prawesti et al. (2010) menunjukkan bahwa profesi saat ini dianggap tidak prestisius bagi generasi muda karena keadaan petani yang cenderung miskin. Keadaan ini juga terjadi di Irlandia dimana anak petani yang telah bermigrasi ke kota untuk menempuh jenjang pendidikan Perguruan Tinggi cenderung tidak menyukai untuk bekerja di sektor pertanian (Cassidy and Mcgrath, 2015).

Kecamatan Trenggalek merupakan salah satu kecamatan yang berada di Kabupaten Trenggalek danmerupakan pusat pemerintahan serta ekonomi di Kabupaten Trenggalek. Letak Kecamatan Trenggalek berada di pusat kota menimbulkan berbagai macam masalah yang dapat menghambat pembangunan dalam sektor pertanian diantaranya adalah berkurangnya minat generasi muda untuk berkecimpung dalam sektor pertanian. Salah satu usaha yang dilakukan oleh Pemerintah Kabupaten Trenggalek untuk meningkatkan minat generasi muda dalam sektor pertanian adalah mendirikan Trenggalek Agropark dengan sistem pertanian terpadu. Trenggalek Agropark akan difungsikan sebagai ruangan terbuka hijau sehingga bisa dimanfaatkan untuk tempat edukasi pertanian dan tempat wisata. Perkembangan objek wisata pada era globalisasi berdampak pada perubahan atau pergeseran motivasi wisatawan untuk memilih objek wisata (Anggraini et al., 2013).

Tujuan dari kajian ini adalah untuk merancang strategi pengembangan Trenggalek Agropark melalui animal based tourism, agar mampu mengatasi tantangan yang akan dihadapi terkait dengan isu kesejahteraan hewan (animal welfare). Animal based tourism merupakan salah satau tipe wisata dimana hewan ternak dijadikan sebagai daya tarik wisata, setting dan objek wisata agar wisatawan mendapatkan pengalaman baru dalam kegiatan wisata. Penerapan animal based tourism mempunyai pengaruh positif seperti meningkatkan pendapatan masyarakat lokal, meningkatkan ketertarikan dan permintaan masyarakat terhadap ternak lokal dan melestarikan plasma nutfah hewan yang semakin berkurang populasinya. Diperlukan konsultasi, partisipasi dan kerja sama antara pemerintah lokal, komunitas bisnis, peternak dan individu untuk mempromosikan atraksi wisata sekaligus melindungi sumberdaya yang sudah ada (Guntoro, 2018).

\section{METODE}

Kajian ini dilaksanakan di Kecamatan Trenggalek Kabupaten Trenggalek pada bulan Mei 2019. Metode yang digunakan adalah dengan menggunakan metode kuantitatif. Data yang digunakan adalah data skunder yang diperoleh dari dokumen-dokumen dari Agropark maupun Dinas Pertanian dan data primer yang diperoleh melalui wawancara dan FGD. Cara penentuan responden menggunakan teknik purposive sampling yaitu 6 orang generasi muda, Kabid dan 2 staf Perencanaan Dinas Pertanian dan Pangan Trenggalek serta 1 orang penyuluh pertanian Kecamatan Trenggalek. Model analisis data yang digunakan adalah analisis SWOT dan QSPM. Tahapan dalam melakukan analisis SWOT adalah 1) Mengumpulkan Faktor internal dan eksternal, kedua aspek tersebut digunakan untuk menyusun strategi pengembangan animal based tourism. Faktor internal dan eksternal yang dikemukakan dalam FGD (Focus Group Discussion) kemudian disaring agar lebih fokus (Fitriani, et al., 2019). 2) Memprioritaskan IFAS dan EFAS Perhitungan diagram kartesius SWOT diperoleh dari angka skor kumulatif IFAS dan EFAS yang dihitung secara matematis (Rangkuti, 2011). 3) Membuat Matriks IE Matriks IE berupa pemetaan total skor IFAS dan EFAS yang dihasilkan dari analisis IFAS dan EFAS. Matriks IE memiliki dua sumbu yang berfungsi sebagai penentu titik ordinat berdasarkan sumbu x (vertikal) diperoleh dari totalskor IFAS dan sumbu y (horizontal) diperoleh dari total skor EFAS. Matriks IE dapat dilihat pada Tabel 1. 4) Analisis IFAS dan EFAS. Faktor internal dan eksternal yang telah diurutkan selanjutnya dimasukkan 
Tabel 1. Matriks IE

\begin{tabular}{|c|c|c|}
\hline 1 & 2 & 3 \\
Grow and Build & Grow and Build & Hold and Maintain \\
\hline 4 & 5 & 6 \\
Grow and Build & Hold and Maintain & Harvest or Divest \\
\hline 7 & 8 & 9 \\
Hold and Maintain & Harvest or Divest & Harvest or Divest \\
\hline
\end{tabular}

ke dalam matriks SWOT. 5) Quantitative Strategic Planning Matrix (QSPM). Pengambilan keputusan didasarkan pada hasil analisis QSPM.

\section{HASIL DAN PEMBAHASAN}

Trenggalek Agropark merupakan suatu wahana edukasi dan wisata pertanian, yang menerapkan konsep pertanian terpadu. Istilah pertanian terpadu berkelanjutan digunakan secara luas dalam berbagai isu dan tujuan. Pemilihan komoditas unggulan, teknologi tepat guna, bantuan teknis, bantuan biaya produksi, pembinaan usaha dan jaringan pasar kemitraan yang tepat akan sangat menentukan pentingnya peran pertanian dalam menyejahterakan masyarakat karena dapat meningkatkan penghasilan petani meskipun dengan lahan dan waktu yang sedikit (Sunarminto, 2014). Manfaat integrasi tanaman-ternak dan tanamanikan dapat disintesis melalui: (1) aspek agronomi yaitu peningkatan kapasitas tanah untuk berproduksi, (2) aspek ekonomi yaitu diversifikasi produk, hasil dan kualitas yang lebih tinggi, serta menurunkan biaya, (3) aspek ekologi yaitu menurunkan serangan hama dan penggunaan pestisida dan pengendalian erosi, (4) aspek sosial yaitu distribusi pendapatan lebih merata (Suwarto dan Efendi, 2015). Diperlukan suatu upaya untuk memperkenalkan sistem pertanian terpadu kepada masyarakat khususnya petani salah satunya adalah dengan mendesain lanskap pertanian terpadu sebagai eduwisata pertanian.

Strategi merupakan tindakan yang bersifat incremental (senantiasa meningkat) dan terus menerus serta dilakukan berdasarkan sudut pandang tentang apa yang diharapkan oleh para pelanggan di masa depan (Suyanto, 2007). Seiring dengan pendapat tersebut, salah satu alasan melibatkan generasi muda dalam perancangan strategi ini karena generasi muda merupakan ujung tombak pembangunan peternakan di masa depan. Strategi merupakan perencanaan yang berisi tentang rangkaian atau rancangan kegiatan untuk mencapai tujuan pendidikan tertentu (Sanjaya, 2006).

Trenggalek Agropark merupakan kawasan pertanian terpadu yang didirikan oleh pemerintah Kabupaten Trenggalek. Salah satu tujuan utama pendirian Trenggalek Agropark adalah sebagai wahana wisata pertanian. Wisata pertanian biasanya didefinisikan dengan mengunjungi pertanian kerja untuk tujuan rekreasi, rekreasi atau pendidikan (Thongma and Leelapattana, 2018). Pengembangan Trenggalek Agropark menjadi wahana wisata pertanian tidak lepas dari tantangan dan ancaman sehingga upaya yang harus dilakukan untuk pengembangan 
Tabel 2 . Pembobotan pada analisis IFAS

\begin{tabular}{|c|c|c|c|c|}
\hline Lingkungan Internal & Bobot & Rating & $\begin{array}{l}\text { Bobot } \mathrm{x} \\
\text { Rating }\end{array}$ & Prioritas \\
\hline \multicolumn{5}{|l|}{ Kekuatan (Strengthness) } \\
\hline $\begin{array}{l}\text { 1. Lokasi Trenggalek Agropark strategis, yaitu berada } \\
\text { di pusat pemerintahan dan ekonomi Kabupaten } \\
\text { Trenggalek }\end{array}$ & 0,11 & 4 & 0,44 & 1 \\
\hline $\begin{array}{l}\text { 2. Agropark baru pertama didirikan di Kabupaten } \\
\text { Trenggalek }\end{array}$ & 0,08 & 4 & 0,32 & 4 \\
\hline $\begin{array}{l}\text { 3. Trenggalek Agropark masuk dalam salah satu } \\
\text { program prioritas Bupati RPJMD }\end{array}$ & 0,10 & 4 & 0,40 & 2 \\
\hline $\begin{array}{l}\text { 4. Trenggalek Agropark merupakan satu-satunya } \\
\text { wahana eduwisata pertanian di Kabupaten } \\
\text { Trenggalek }\end{array}$ & 0,07 & 4 & 0,28 & 6 \\
\hline $\begin{array}{l}\text { 5. Terdapat SDM pendamping sesuai dengan bidang } \\
\text { pertanian dan peternakan }\end{array}$ & 0,08 & 4 & 0,32 & 5 \\
\hline $\begin{array}{l}\text { 6. Ternak yang dipilih sebagai koleksi merupakan } \\
\text { ternak unggul }\end{array}$ & 0,09 & 4 & 0,36 & 3 \\
\hline Jumlah Kekuatan & & & 2,12 & \\
\hline \multicolumn{5}{|l|}{ Kelemahan (Weakness) } \\
\hline 1. Tanah di Agropark merupakan tanah masam & 0,07 & 1 & 0,07 & 5 \\
\hline 2. Ternak koleksi saat ini masih kurang & 0,06 & 1 & 0,06 & 6 \\
\hline $\begin{array}{l}\text { 3. Struktur organisasi pengelola Trenggalek Agropark } \\
\text { belum efektif }\end{array}$ & 0,10 & 3 & 0,30 & 1 \\
\hline $\begin{array}{l}\text { 4. Waktu pendampingan oleh SDM pendamping } \\
\text { belum optimal }\end{array}$ & 0,09 & 3 & 0,27 & 2 \\
\hline $\begin{array}{l}\text { 5. Anggaran pembiayaan bidang pertanian, peternakan } \\
\text { dan perikanan masih terpisah }\end{array}$ & 0,08 & 3 & 0,24 & 3 \\
\hline $\begin{array}{l}\text { 6. Sarana dan prasarana di Trenggalek Agropark } \\
\text { masih banyak yang belum dibangun }\end{array}$ & 0,07 & 2 & 0,14 & 4 \\
\hline Jumlah Kelemahan & & & 1,08 & \\
\hline Total & 1 & & 3,20 & \\
\hline
\end{tabular}

Sumber: Data primer yang diolah, 2019.

tentunya tidak mudah. Banyak jenis kegiatan yang ditawarkan di pertanian ditandai sebagai wisata pertanian, termasuk yang terkait dengan apresiasi alam dan pertanian, kegiatan pendidikan, rekreasi panen dan kegiatan rekreasi umum di luar ruangan (Barbieri and Mshenga; McGehee and Kim; Tew and Barbieri dalam Thongma and Leelapattana, 2018). Faktor internal dan faktor eksternal yang dianalisa cukup banyak (Tabel 2 dan
Tabel 3). Faktor-faktor tersebut diperoleh dari FGD dan wawancara dengan informan.

Faktor internal dari Trenggalek Agropark terbagi menjadi dua yaitu kekuatan dan kelemahan (Tabel 2). Berdasarkan hasil FGD diperoleh 6 kekuatan dan 6 kelemahan. Faktor-faktor tersebut kemudian diberi bobot dengan skala $0,0-1,0$ dan diberi rating dengan skala $1-4$. Langkah selanjutnya yaitu mengalikan bobot dan rating, semakin 
Tabel 3. Pembobotan pada analisis EFAS

\begin{tabular}{|c|c|c|c|c|}
\hline Lingkungan Eksternal & Bobot & Rating & $\begin{array}{l}\text { Bobot } \mathrm{x} \\
\text { Rating }\end{array}$ & Prioritas \\
\hline \multicolumn{5}{|l|}{ Peluang (Opportunities) } \\
\hline $\begin{array}{l}\text { 1. Trenggalek Agropark dapat dijadikan sebagai } \\
\text { wahana study lapang siswa }\end{array}$ & 0,12 & 4 & 0,48 & 1 \\
\hline $\begin{array}{l}\text { 2. Tempat pengembangan produk-produk } \\
\text { peternakan }\end{array}$ & 0,09 & 3 & 0,27 & 4 \\
\hline $\begin{array}{l}\text { 3. Sarana dan prasarana dapat dioptimalkan } \\
\text { dengan maksimal mengingat dukungan } \\
\text { pemerintah sangat baik terhadap Trenggalek } \\
\text { Agropark }\end{array}$ & 0,10 & 3 & 0,30 & 3 \\
\hline $\begin{array}{l}\text { 4. Trenggalek Agropark dapat digunakan sebagai } \\
\text { tempat pemasaran produk pertanian dan } \\
\text { peternakan yang dihasilkan dari petani dan } \\
\text { peternak }\end{array}$ & 0,08 & 3 & 0,24 & 5 \\
\hline $\begin{array}{l}\text { 5. Pusat edukasi usaha peternakan perkotaan di } \\
\text { Kabupaten Trenggalek. }\end{array}$ & 0,11 & 4 & 0,44 & 2 \\
\hline $\begin{array}{l}\text { 6. Penerapan prinsip animal walfare dalam } \\
\text { wahana eduwisata peternakan }\end{array}$ & 0,08 & 2 & 0,16 & 7 \\
\hline $\begin{array}{l}\text { 7. Pelaksanaan kontes ternak (kambing, burung, } \\
\text { bekisar) }\end{array}$ & 0,10 & 2 & 0,20 & 6 \\
\hline Jumlah Peluang & & & 2,09 & \\
\hline \multicolumn{5}{|l|}{ Ancaman (Threats) } \\
\hline $\begin{array}{l}\text { 1. Trenggalek Agropark masuk dalam kawasan } \\
\text { ekonomi terbangun, dimana nantinya } \\
\text { diperkirakan akan terjadi kesulitan dalam } \\
\text { perolehan air irigasi }\end{array}$ & 0,09 & 2 & 0,18 & 3 \\
\hline $\begin{array}{l}\text { 2. Partisipasi dan sinergi dengan masyarakat } \\
\text { masih kurang }\end{array}$ & 0,11 & 3 & 0,33 & 2 \\
\hline $\begin{array}{l}\text { 3. Lokasi Trenggalek Agropark merupakan daerah } \\
\text { rawan banjir }\end{array}$ & 0,12 & 4 & 0,48 & 1 \\
\hline Jumlah Ancaman & & & 0,99 & \\
\hline Total & 1 & & 3,08 & \\
\hline
\end{tabular}

Sumber: Data primer yang diolah, 2019.

tinggi hasilnya maka fator tersebut semakin diprioritaskan.

Faktor eksternal dari Trenggalek Agropark terbagi menjadi dua yaitu ancaman dan peluang (Tabel 3). Berdasarkan hasil FGD diperoleh 7 peluang dan 3 ancaman. Faktorfaktor tersebut kemudian diberi bobot dengan skala $0,0-1,0$ dan diberi rating dengan skala
$1-4$. Langkah selanjutnya yaitu mengalikan bobot dan rating, semakin tinggi hasilnya maka fator tersebut semakin diprioritaskan.

Berdasarkan Tabel 2 dan Tabel 3 dapat disimpulkan bahwa jumlah faktor kekuatan adalah 2,12; jumlah faktor kelemahan adalah 1,08; jumlah faktor peluang adalah 2,09 dan jumlah faktor ancaman adalah 0,99 . Selisih 


\section{Gambar 1. Diagram SWOT}

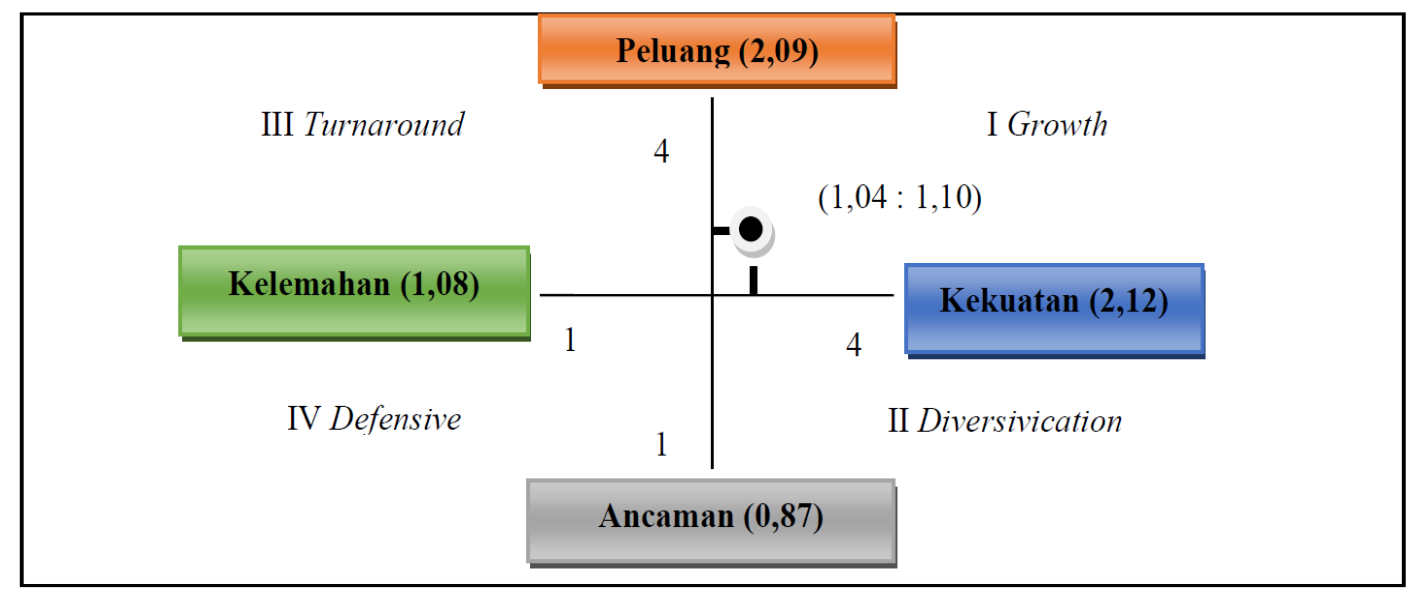

Gambar 1. Diagram SWOT (Sumber: Data primer yang diolah, 2019)

faktor internal kekuatan dan kelemahan adalah 1,04 dimana kekuatan lebih besar dari pada kelemahan. Selisih faktor eksternal peluang dan ancaman adalah sebesar 1,10 dimana peluang lebih besar dari pada ancaman. Hasil perhitungan nilai internal dan eksternal yang diperoleh dari pembobotan yang diberikan melalui FGD dapat dilihat pada Gambar 1.

Keberadaan Trenggalek Agropark saat ini berada pada kuadran I yaitu StrenghtOpportunities (S-O) yang menandakan kondisi Agropark kuat dan berpeluang (Gambar 1). Strategi yang direkomendasikan dalah growth atau progresif dimana keadaan Trenggalek Agropark prima dan mantab sehingga dapat terus melakukan pertumbuhan dan perkembangan dalam meraih kemajuan secara maksimal. Langkah selanjutnya yaitu membuat Matriks IE, yang dapat dilihat pada Gambar 2.

Berdasarkan Tabel 2 dan Tabel 3 pemberian bobot IFAS dan EFAS dapat disusun selanjutnya matriks IE (Gambar 2). Nilai rata-rata IE diperoleh dari total skor internal faktor $(3,20)$ dan total skor eksternal faktor $(3,08)$. Nilai tersebut menunjukkan pada kuandran I, strategi yang dibutuhkan adalah grow and built strategi. Grow and built strategy menunjukkan bahwa perusahaan butuh strategi untuk tumbuh lebih baik dan dapat mengembangkan perusahaan menjadi lebih baik (Setyorini et al., 2016).

$$
\text { Langkah selanjutnya yaitu }
$$
mengkombinasikan faktor-faktor internal dengan faktor-faktor eksternal melalui matriks SWOT. Adapun strategi yang dihasilkan yaitu S-O yang diperoleh dengan cara memaksimalkan kekuatan internal dan memanfaatkan peluang eksternal yang ada. Strategi S-T diperoleh dengan cara memaksimalkan kekuatan internal untuk meminimalkan ancaman. Strategi W-O diperoleh dengan cara meminimalkan kelemahan internal dan memanfaatkan peluang eksternal yang ada. Strategi W-T diperoleh dengan cara meminimalkan kelemahan internal dan ancaman eksternal yang ada. Berdasarakan hasil diagram SWOT (Gambar 1) dan Matriks IE (Gambar 2) tentang posisi Trenggalek Agropark saat ini berdasarkan faktor internal dan faktor eksternal maka strategi yang akan diterapkan untuk pengembangan Trenggalek Agropark adalah strategi S-O.

Terdapat 5 strategi S-O yang dihasilkan yaitu Strategi S-O pertama adalah melengkapi sarana dan prasarana serta pengadaan diklat pada SDM guna pengoptimalan pemanfaatan sarana dan prasarana yang telah ada (S2, S5, O3). Strategi ini merupakan aspek 
Total Skor IFE $(3,20)$

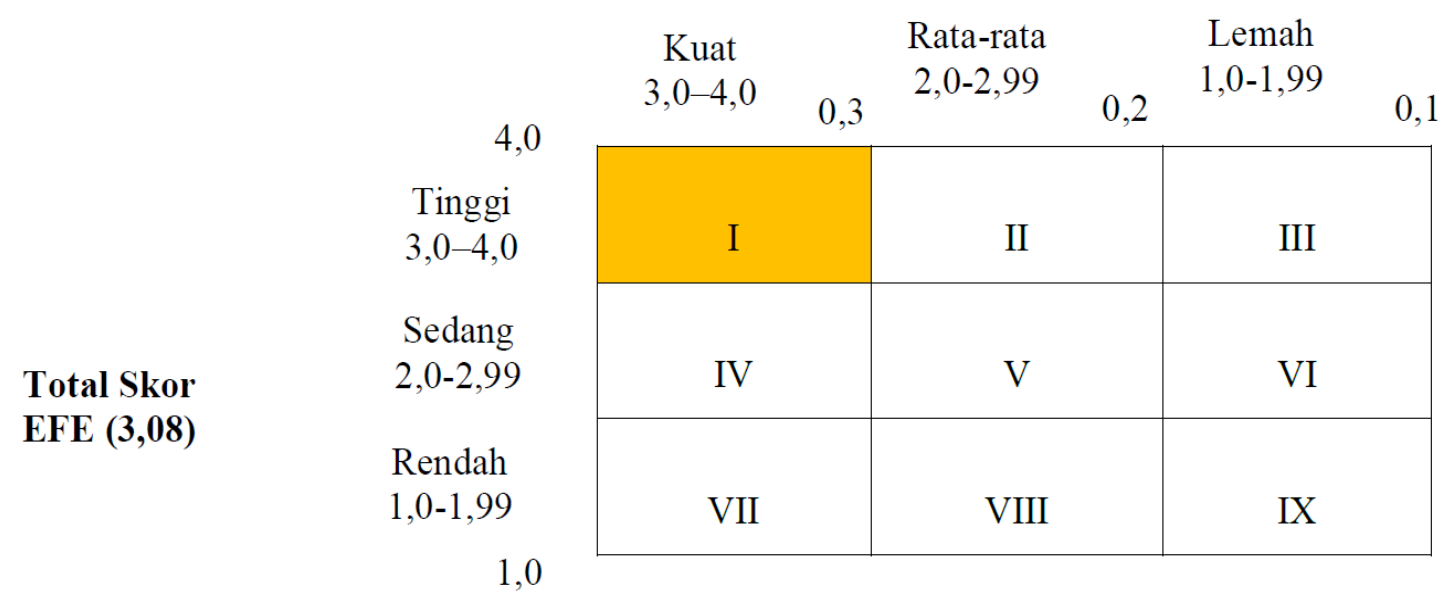

Gambar 2. Matriks IE (IFAS dan EFAS)

amenitas pada tripel A. Fasilitas atau sarana dan prasarana yang terdapat di Trenggalek Agropark adalah toilet, kantin, tempat parkir yang luas, saung dan kantin yang belum berfungsi dengan maksimal. Adapun fasilitas penunjang seperti hotel dan resort, toko dan warung makan milik masyarakat serta ketersediaan transportasi darat yang mudah dijangkau dengan letak Trenggalek Agropark.

Strategi S-O kedua yaitu membangun kandang umbaran dan melakukan penanaman rumput guna mendukung penerapan prinsip kesejahteraan hewan (S3, S6, O6, O7). Lima prinsip dalam penerapan animal welfare adalah bebas dari rasa lapar dan haus; bebas dari rasa sakit dan tidak nyaman; bebas dari rasa sakit, luka dan penyakit; bebas mengekspresikan perilaku normal dan bebas dari rasa stress dan tertekan. Kandang umbaran dapat mendukung ternak dalam mengekspresikan perilaku normal seperti halnya di habitat aslinya. Penanaman rumput dilakukan untuk membantu memenuhi pakan ternak agar terbebas dari rasa lapar.

Strategi S-O ketiga yaitu menyediakan showroom produk pertanian dan peternakan yang dihasilkan oleh petani dan peternak di Kabupaten Trenggalek (S1, O4, O5). Showroom produk pertanian dan peternakan dapat didirikan di destinasi terakhir Trenggalek
Agropark, sehingga pengunjung dapat membeli oleh-oleh berupa produk pertanian dan peternakan. Trenggalek Agropark dapat bekerjasama dengan kelompok tani dalam hal pemasaran produk.

Strategi S-O keempat yaitu perlu adanya guide khusus untuk membimbing pengunjung yang dapat memberikan edukasi pertanian secara langsung (S1, S4, O1, O5). Guide atau pemandu yang bertugas untuk menjelaskan setiap titik destinasi wisata sangat diperlukan dalam wisata edukasi. Guide juga bertugas untuk mendampingi pengunjung di Trenggalek Agropark ketika sedang beredukasi, sehingga ilmu yang diberikan dapat diterima oleh pengunjung. Guide ini, harus dipilih dari orang yang ahli di bidang pertanian dan peternakan.

Strategi S-O kelima yaitu pengadaan event-event (kontes ternak, festival dan pameran) terjadwal sebagai wadah untuk memperkenalkan komoditas peternakan kepada masyarakat dan penerapan prinsip kesejahteraan hewan (S1, S6, O1, O2, O6, O7). Pengadaan event-event tersebut merupakan salah satu atraksi yang dapat ditawarkan di Trenggalek Agropark dengan berbagai pengalaman yang bisa dinikmati wisatawan. Beberapa pengalaman yang dapat ditawarkan adalah memberi makan kelinci, 
memberi makan dan minum ternak kambing dan sapi sehingga mereka diizinkan untuk berinteraksi langsung dengan ternak selain itu, aktivitas dalam animal tourism dapat berupa tour peternakan, terlibat dalam farmer activity (one day be a farmer) dan juga berfoto dengan ternak.

Pengadaan kontes ternak perlu memperhatikan prinsip kesejahteraan hewan. Kesejahteraan hewan merupakan bentuk kepedulian dan perlakuan manusia pada masing-masing hewan, dalam meningkatkan kualitas hidup hewan secara individual (Rawendra et al., 2019). Lima azas kebebasan dalam kesejahteraan hewan yang dapat diterapkan dalam konsep animal based tourism adalah bebas dari rasa lapar dan haus; bebas dari rasa sakit dan tidak nyaman; bebas dari rasa sakit, luka dan penyakit; bebas mengekspresikan perilaku normal dan bebas dari rasa stress dan tertekan (Rawendra et al., 2019). Salah satu contoh kontes yang tidak sesuai dengan prinsip kesejahteraan hewan adalah sabung ayam, sehingga kontes ini tidak boleh diterapkan di Trenggalek Agropark.

Trenggalek Agropark mempunyai potensi berkembang dimasa mendatang sebagai wisata kota. Pengembangan Wisata Kota akan menjadi trend menarik dimasa depan berdasarkan banyak alasan yang rasional, namun demikian potensi yang bagus akan lebih berhasil jika dapat dikembangkan dan dikelola dengan manajemen kota yang terintegrasi dalam konsep totalitas produk wisata yang saling terkait dengan yang lainnya. Minimal ada empat unsur yang harus diintegrasikan yakni unsur atraksi atau daya tarik wisata, unsur amenitas atau infrastruktur dan fasilitas pendukung, unsur aksesibilitas berupa publik transportasi yang baik, manajemen transportasi yang efesien dan efektif. Dan integrasi yang tidak kalah pentingnya adalah unsur ensileri yang merupakan softkills dari totalitas produk wisata kota sebagai pengendali, pengeoperasi, dan evaluator yang menerapkan etika pembangunan yang berkelanjutan (Utama, 2013).
Lima strategi SO yang telah dirumuskan selanjutnya di analisis dengan menggunakan QSPM untuk menentukan prioritas strategi. Analisis QSPM dilakukan dengan memberikan bobot dan ketertarikan (AS) pada setiap strategi, kemudian mengalikan bobot dengan ketertarikan yang disebut sebagai TAS. Urutan prioritas tidak sama dengan urutan strategi, hal ini disebabkan oleh estimasi tingkat kepentingan, pengaruh serta dampak akhir yang dapat diberikan dari setiap pertimbangan terhadap masing-masing strategi yang telah dirumuskan (Fitriani et al., 2019). Semakin tinggi total skor strtegi mempunyai tingkat prioritas semakin tinggi juga. Urutan prioritas yang dihasilkan, nilai bobot, AS dan TAS. Berdasarkan strategi yang dapat diprioritaskan untuk pengembangan Trenggalek Agropark adalah sebagai berikut:

1. Melengkapi sarana dan prasarana serta pengadaan diklat pada SDM guna pengoptimalan pemanfaatan sarana dan prasarana yang telah ada (S2, S5, O3).

2. Membuat kandang umbaran dan penanaman HPT guna mendukung penerapan prinsip kesejahteraan hewan (S3, S6, O6, O7).

3. Menyediakan showroom untuk memasarkan produk pertanian dan peternakan yang dihasilkan oleh petani dan peternak di Kabupaten Trenggalek (S1, O4, O5).

4. Perlu adanya guide khusus untuk membimbing pengunjung yang dapat memberikan edukasi pertanian secara langsung (S1, S4, O1, O5).

5. Pengadaan event-event (kontes ternak, festival dan pameran) terjadwal sebagai wadah untuk memperkenalkan komoditas peternakan kepada masyarakat dan penerapan prinsip kesejahteraan hewan.

\section{KESIMPULAN}

Strategi yang digunakan pengembangan Trenggalek Agropark melalui animal based tourism dapat dilakukan 
dengan cara memanfaatkan kekuatan secara maksimal (strength) untuk merebut peluang (opportunities). Berdasarkan hasil analisis SWOT dan QSPM diapatkan 5 (lima) strategi yaitu melengkapi sarana dan prasaran serta melakukan diklat bagi SDM pendamping, menyiapkan lahan untuk penanaman HPT guna mendukung penerapan prinsip kesejahteraan hewan (animal welfare), menyediakan showroom untuk memasarkan pruduk pertanian dan peternakan yang telah dihasilkan oleh petani/peternak Kabupaten Trenggalek, kedepannya Trenggalek Agropark membutuhkan guide yang bertugas untuk mendampingi pengunjung agar mendapatkan edukasi pertanian dan peternakan, mengadakan event-event peternakan terjadwal sebagai wadah untuk memperkenalkan komoditas peternakan kepada masyarakat dan penerapan prinsip kesejahteraan hewan. Seluruh strategi yang telah dirumuskan layak untuk diupayakan dalam membantu pengembangan Trenggalek Agropark melaui animal based tourism. Dukungan dari Pemerintah Kabupaten Trenggalek dan Dinas terkait diperlukan guna perwujudan dari strategi yang telah dibentuk demi pengembangan Trenggalek Agropark untuk menjadi lebih baik kedepannya.

\section{DAFTAR PUSTAKA}

Anggraini, L., E. Kurnia, dan A. Warnaen. 2013. Strategi Pengembangan Kampung Wisata Aren Berbasis Community Based Tourism (CBT) di Desa Gelangsar Kec. Gunungsari. Prosiding Seminar Nasional Pertanian. 371-382.

Cassidy, A. and B. Mcgrath. 2015. Farm, Place and Identity Construction Among Irish Farm Youth Who Migrate. Journal of Rural Studies 37(1): 20 - 28.

Fitriani, A., Alim, S. dan Herlina, L. 2019. Strategi Pengembangan Usaha Pemeliharaan Ayam Pelung di Kabupaten Cianjur. Vol 21(1): 34-50.
Guntoro, B. 2018. Potentials Challenges of Animal Attractions in Developing Animal Based Tourism. International Conference on Food and Agricultural.

Nugroho, A. Dwi., Waluyati, L. Rahayu, dan Jamhari. 2018. Upaya Memikat Generasi Muda Bekerja pada Sektor Pertanian di Daerah Istimewa Yogyakarta. Vol 6 (1): 76-95.

Prawesti, N., R. Witjaksono, dan A. B. Raya. 2010. Motivasi Anak Petani menjadi Petani. Agro Ekonomi 17(1): 1118.

Rangkuti, F. 2011. SWOT Balanced Scorecard (Teknik Menyusun Strategi Korporat yang Efektif Plus Cara Mengelola Kinerja dan Resiko). Gramedia Pustaka Utama. Jakarta.

Rawendra, R., Indarwati, R. dan Muda, I. 2019. Materi Diklat Pra Assesmen Juru Sembelih Halal. Media Nusa Creativ. Malang.

Sanjaya, W. 2006. Strategi Pembelajaran (Berorientasi Standar Proses Pendidikan). Kencana Prenada Media Group. Jakarta.

Setyorini, H., Effendi, M. dan Santoso, I. 2016. Analisis Strategi Pemasaran Menggunakan Matriks SWOT dan QSPM (Study Kasus: Restoran WS Soekarno Hatta Malang). Jurnal Teknologi dan Manajemen Agroindustri. Vol 5 (1): 46-53.

Sunarminto. B. H. 2014. Pertanian Terpadu Untuk Mendukung Kedaulatan Pangan Nasional. Gadjah Mada University Press. Yogyakarta.

Suwarto, A., A. T. dan Effendi, I. 2015. Perancangan Model Pertanian Terpadu Tanaman-Ternak dan Tanaman-Ikan di Perkampungan Teknologi Telo, Riau. Jurnal Agronomi Indonesia. Vol 23, 168-177.

Suyanto, M. 2007. Marketing Strategy Top Brand Indonesia. Yogyakarta: Andi Offset. 
Thongma, W. and Leelapattana, W. 2018. Farm Tourism Management in Thailand: Case Study of Chiang Mai Province. International Conference on Food and Agricultural.
Utama, I G. B. R. 2013. Pengembangan Wisata Kota sebagai Pariwisat Masa Depan Indonesia. Seminar Nasional UNHI. Denpasar. 